\title{
STRUCTURE-BASED PREDICTIVE MODEL FOR COAL CHAR COMBUSTION
}

Quarterly Technical Report

Reporting Period: 04/01/1998 - 06/30/1998

Authors: Robert H. Hurt, Joseph M. Calo, Robert H. Essenhigh, Christopher M. Hadad

Report Issue Date: 09/11/1998

DE-FG22-96PC96249--07

Division of Engineering

Box D

Brown University

Providence, RI 02912-9104

Robert H. Essenhigh

Depts. of Mechanical Engineering \& Chemistry

The Ohio State University

206 W. 18th Avenue

Columbus, OH 43210-1107 


\section{Disclaimer}

This report was prepared as an account of work sponsored by an agency of the United States Government. Neither the United States Government nor any agency thereof, nor any of their employees, makes any warranty, express of implied, or assumes any legal liability or responsibility for the accuracy, completeness, or usefulness of any information, apparatus, product, or process disclosed, or represents that its use would not infringe privately owned rights. Reference herein to any specific commercial product, process, or service by trade name, trademark, manufacturer, or otherwise does not necessarily constitute or imply its endorsement, recommendation, or favoring by the United States Government or any agency thereof. The views and opinions of authors expressed herein do not necessarily state or reflect those of the United States Government or any agency thereof. 


\section{TABLE OF CONTENTS}

EXECUTIVE SUMMARY

PROJECT DESCRIPTION ..................................................... 4

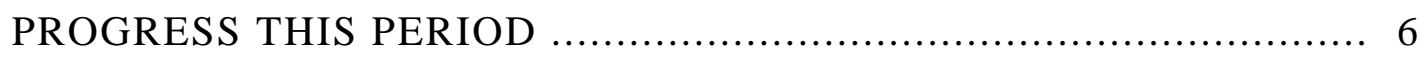

Brief Summary of Activities ...................................... 6

Detailed Discussions of Progress

Section 1: Impact of Zone 1/ Zone 2 Transition on Pulverized Char Combustion .............. 7

Section 2: Order Length Scales in Carbon Structure Simulations............... 11

Section 3: Computational Chemistry ................. 14

Section 4: Combustion Experiments in Contrasting Flame Types .................... 18

MILESTONE PLAN attached

MILESTONE LOG attached 


\section{EXECUTIVE SUMMARY}

Progress was made this period on a number of tasks. A significant advance was made in the incorporation of macrostructural ideas into high temperature combustion models. Work at OSU by R. Essenhigh in collaboration with the University of Stuttgart has led to a theory that the zone I / II transition in char combustion lies within the range of conditions of interest for pulverized char combustion. The group has presented evidence that some combustion data, previously interpreted with zone II models, in fact takes place in the transition from zone II to zone 1. This idea was used at Brown to make modifications to the CBK model (a char kinetics package specially designed for carbon burnout prediction, currently used by a number of research and furnace modeling groups in academia and industry). The resulting new model version, CBK8, shows improved ability to predict extinction behavior in the late stages of combustion, especially for particles with low ash content. The full development and release of $\mathrm{CBK} 8$, along with detailed descriptions of the role of the zone $1 / 2$ transition will be reported on in subsequent reports. ABB-CE is currently implementing CBK7 into a special version of the CFD code Fluent for use in the modeling and design of their boilers. They have been appraised of the development, and have expressed interest in incorporating the new feature, realizing full CBK8 capabilities into their combustion codes.

The computational chemistry task at OSU continued to study oxidative pathways for PAH, with emphasis this period on heteroatom containing ring compounds. Preliminary XPS studies were also carried out. Combustion experiments were also carried out at OSU this period, leading to the acquisition of samples at various residence times and the measurement of their oxidation reactivity by nonisothermal TGA techniques.

Several members of the project team attended the Carbon Conference this period and made contacts with representatives from the new FETC Consortium for Premium Carbon Products from Coal. Possibilities for interactions with this new center will be explored. Also this period, an invited review paper was prepared for the 27th International Symposium on Combustion, to be held in Boulder, Colorado in August. The paper is entitled; "Structure, Properties, and Reactivity of Solid Fuels," and reports on a number of advances made in this collaborative project. 


\section{PROJECT DESCRIPTION}

The problem of excessive unburned carbon in fly ash could be better managed if designers and users of combustion systems could determine the reactivity of a given char from basic coal properties, avoiding the need to resort to expensive full-scale testing. Establishing a mechanistic link between coal properties and fuel behavior has long been a goal of the coal research community, as such a capability would find numerous uses in predictive tools and optimization tools for coal technologies. Such a predictive capability will not likely be achieved through incremental improvements to current models - new, more fundamental approaches are needed such as the structure-based approach, which we believe has the long term potential to make the required mechanistic links between coal properties and char behaviors.

The overall objective of this project is to carry out the fundamental research needed to develop a first-generation, structure-based model of coal char combustion. The project involves combustion experimentation at a variety of scales, theoretical treatments of surface chemistry, and the development and refinement of advanced modeling techniques describing solid-state transformations in coal chars. The fundamental modeling approaches taken here may also produce auxiliary benefits for other coal technologies, including cokemaking, liquefaction, activated carbon production and use, and carbon materials manufacture (fibers, composites, graphite, etc.). The crystalline structure of carbons and its evolution during processing plays an important role in each of these diverse applications.

This combined experimental and theoretical approach will result in a first-generation, structurebased model that is a significant improvement over empirical models in its ability to:

- predict, from fundamental principals, the rank-dependence of char reactivity

- predict the dependence of char reactivity on heat treatment conditions

- describe reaction kinetics in a wide variety of combustion / gasification environments

\section{Task Structure}

This Project consists of the following three interrelated tasks:

\section{Task 1. Project Management}

This task involves reporting, documentation, coordination of effort at the three participating universities, and interactions with the advisory board.

\section{Task 2. Development of Structure-Based Models}

The objective of this is the development of new models that describe the combustion process on a more fundamental basis. Dynamic models will be formulated that describe the evolution of char crystal structures in flames, and fundamental computational treatments of oxidative attack on model PAH and graphitic structures will be carried out. This task also includes laboratory-scale 
experiments designed to establish link between char structure and oxidation reactivity, and a direct investigation of carbon crystalline rearrangements by in- situ, hot-stage HRTEM.

\section{Task 3. Experiments in Practical Combustion Systems}

This represents a parallel effort to investigate and document the importance of thermal history effects on char structure and reactivity in well-controlled and characterized coal flames. Comparative experiments will be carried out on two reactor facilities with widely varying flame type and the properties and reactivities of the chars characterized.

\section{Project Team}

The project involves three universities (Brown, Ohio State, and Boston University), in order to couple engineering experts in coal combustion and carbon science (at Brown and Ohio State) with research groups in the pure sciences specializing in modern computational chemistry (OSU) and in solid state physics (BU). The multidisciplinary team will apply modern scientific tools to the challenging technological problem of linking char combustion behavior with coal properties and processing conditions.

The project is supported by an advisory panel assembled from industry, academia, and the national laboratories with a wide range of expertise. The panel members are:

$\begin{array}{ll}\text { Hamid Farzan } & \text { Babcock and Wilcox Co } \\ \text { Alan Kerstein } & \text { Sandia National Laboratories } \\ \text { Harry Marsh } & \text { University of Alicante } \\ \text { Arun Mehta } & \text { Electric Power Research Institute } \\ \text { Richard McCreery } & \text { Ohio State University } \\ \text { Nsakala Nsakala } & \text { ABB Combustion Engineering } \\ \text { Stuart Daw } & \text { Oak Ridge National Labs }\end{array}$




\section{PROGRESS THIS PERIOD}

Progress was made this period in a number of areas. A significant advance was made in the incorporation of macrostructural ideas into high temperature combustion models. Work at OSU by R. Essenhigh in collaboration with the University of Stuttgart has led to a theory that the zone I / II transition in char combustion lies within the range of conditions of interest for pulverized char combustion. The group has presented evidence that some combustion data, previously interpreted with zone II models, in fact takes place in the transition from zone II to zone 1. This idea was used at Brown to make modifications to the CBK model (a char kinetics package specially designed for carbon burnout prediction, currently used by a number of research and furnace modeling groups in academia and industry). The resulting new model version, CBK8, shows improved ability to predict extinction behavior in the late stages of combustion, especially for particles with low ash content. This work is described briefly below. The full development and release of CBK8, along with detailed descriptions of the role of the zone 1/2 transition will be reported on in subsequent reports. ABB-CE is currently implementing CBK7 into a special version of the CFD code Fluent for use in the modeling and design of their boilers. They have been appraised of the development, and have expressed interest in incorporating the new feature, realizing full CBK8 capabilities into their combustion codes.

Also, the carbonization modeling activity carried out in collaboration with Alan Kerstein was continued, leading to development of a technique for extracting the length scale of order from the numerical simulations (see Fig. 3 and discussion in section 2 below).

The computational chemistry task at OSU continued to study oxidative pathways for PAH, with emphasis this period on heteroatom containing ring compounds. Preliminary XPS studies were also carried out. Both activities are described in more detail below. Combustion experiments were also carried out at OSU this period, leading to the acquisition of samples at various residence times and the measurement of their oxidation reactivity by nonisothermal TGA techniques. This work is also described in more detail below.

Several members of the project team attended a conference on Carbon Materials this period and presented papers on HRTEM characterization of coal chars and on the model of carbonization as a kinetic liquid crystal transition. The Carbon Conference provides a unique opportunity to convey the results of this project to a larger audience interested in the broad spectrum of carbon materials. At the conference, contacts were made with representatives from the new FETC Consortium for Premium Carbon Products from Coal.

Also this period, an invited review paper was prepared for the 27th International Symposium on Combustion, to be held in Boulder, Colorado in August. The paper is entitled; "Structure, Properties, and Reactivity of Solid Fuels," and reports on a number of advances made in this collaborative project. 


\section{DETAILED DISCUSSIONS OF PROGRESS}

\section{Section 1: Impact of Zone 2 to Zone 1 Transition on Carbon Burnout Profiles}

\section{$\underline{\text { OSU / University of Stuttgart collaboration }}$}

Dieter Förtsch from the Institut für Verfahrenstechnik und Dampkesselwesen (IVD) at the University of Stuttgart made a recent visit to OSU for collaborative work with Prof. Essenhigh within our IEA Annex I agreement on char combustion and carbon burnout. During his stay at OSU, Dieter and Prof. Essenhigh performed a theoretical analysis indicating that the Zone I reaction mode ${ }^{\dagger}$ can occur under some conditions that arise in pulverized coal combustion. This work will be reported on in more detail in subsequent reports. Based on the OSU / Stuttgart work, modifications were made at Brown to the Carbon Burnout Kinetic Model (CBK Version 7) to test the implications of this finding to the carbon burnout process. This work is ongoing, but the early results are described below, starting with background on CBK7.

\section{$\underline{\text { CBK Version } 7}$}

The Carbon Burnout Kinetic Model, CBK, is a char combustion kinetics package specifically designed for description of the carbon burnout process in industrial pulverized coal combustion [Hurt et al., 1998]. It was developed under DOE funding at Sandia National Laboratories and at Brown University, and is being used or currently implemented in a number of academic and industrial groups around the U.S. These groups include:

- EPRI, who have used the code in the LOI algorithm for the commercial software package The NOx LOI PREDICTOR.

- ABB-CE who are implementing a version of CBK into Fluent, for in-house furnace modeling activities,

- Reaction Engineering International, and Professor Phil Smith at the University of Utah, who are implementing a version of $\mathrm{CBK}$ into their multi-dimensional comprehensive furnace simulation tools.

\footnotetext{
$\dagger$ The Zone I mode refers to strict chemical reaction control, Zone II is chemical reaction control influenced by pore diffusion limitations within the reacting particle, and Zone III refers to reaction controlled by boundary layer diffusion. Traditional models of high temperature char combustion [e.g. Field, 1970; Hurt and Mitchell, 1992] assume that the reaction occurs in either Zone II, Zone III, or the transition from Zones II to III. The mathematical formulation used in these models is not applicable if the reaction occurs in Zone I or in the transition from Zone II to Zone I.
} 
The current version, CBK7, is based on the single-film kinetic model of Mitchell and Madsen [1983] with the rank-dependent reactivity correlation of Hurt and Mitchell [1992], modified to include four additional submodels:

1 a submodel of thermal annealing that generalizes char reactivity parameters to temperature histories different from the ones under which they were originally measured,

2. a statistical kinetic submodel, that accounts for particle-to-particle variations in reactivity and initial char density,

3. a submodel of ash inhibition, which further reduces burning rates in the late stages of combustion, and

4. generalized correlations allowing estimation of all input parameters from readily-available coal properties (proximate and ultimate).

The first three submodels cause char deactivation as a function of temperature, time, and conversion, and allow the model to describe the late stages of combustion and also the behavior of chars that have been exposed to varying degrees of high temperature heat treatment. The model has been validated against entrained flow reactor data from Sandia National Laboratories, the U.K. utility PowerGen, and a variety of data sets on thermal deactivation.

More recent work at Sandia National Laboratories has revealed a phenomenon that cannot be adequately described by CBK7. Captive particle imaging studies at $1250 \mathrm{~K}$ gas temperature on a variety of coal and biomass samples show that late stage extinction behavior is rank dependent [Hurt and Davis, 1998]. The bituminous coal chars show pronounced extinction behavior followed by an extended final burnout phase, while the biomass-derived samples and the low rank coals do not - they typically burn at or near their maximum particle temperature up to the very latest stages. The same trend is reflected in the higher temperature data from entrained flow reactors, although it is less pronounced. At the higher temperatures, the break in the mass loss profiles that signals the transition to the late stages of burning typically comes at higher conversion for low rank coals than for bituminous coals (see Figs. 1 and 2 for an example). CBK7 predicts extinction for both cases, but cannot predict the rank-dependent differences. In addition, in captive particle imaging studies, extinction is often observed for particles that contain very little mineral matter. The main mechanism in CBK7 capable of producing early extinction is the mineral / carbon interaction, and in general, CBK7 cannot predict abrupt extinction events for single particles with very low ash contents. An additional mechanism is needed to describe these important effects.

An analysis was performed this period to assess whether the models predictive capabilities in these areas could be improved by a complete accounting for the Zone II to Zone I transition, based on the results obtain by OSU and IVD. An intrinsic formulation was integrated into CBK7 based on the classical theory of Thiele and the parallel path pore model for estimation of effective diffusion coefficients. In this version of the model (CBK8) the original Zone II kinetic parameters are used in a preprocessing subroutine to compute an initial mass specific intrinsic reactivity, $\mathrm{kS}$, valid in the early stages of combustion. The parameter $\mathrm{kS}$ is then used in the code together with the equations describing pore diffusion to predict overall burning rates at any instant For cases involving high temperatures $(>1600 \mathrm{~K})$, reactive chars, and large particles $(>50 \mu \mathrm{m})$, reaction is clearly predicted to be in Zone II, and the original CBK7 predictions are reproduced by CBK8. Under some conditions, however, favored by low gas temperatures, low char reactivities, and 
small particle size, the reaction can deviate from Zone II behavior, or even exhibit strict Zone I behavior in which the oxygen penetrates fully into the porous matrix without significant concentration gradients. Under these conditions, the two model versions yield different predictions, with CBK7 overpredicting the rate due to the incorrect Zone II assumption.

One important implication of the new model formulation is for late stage behavior, as seen in Figs. 1 and 2. These figures show data taken in the hot wall entrained flow reactor at Sandia, reported in Hurt et al. [1998], in comparison with predictions of the new model, CBK8. As Illinois \#6 coal char burns in Fig. 1, the combination of reduced size, temperature, and reactivity (due to the combination of annealing, concentration of less reactive particles, and ash interactions), leads to a pronounced break in the mass loss curve at about $80 \%$ conversion, in good agreement with measurement. By repeating the calculation with the ash inhibition model off, it is clear that the ash submodel is not responsible for the effect. Indeed, after the char particles undergo near extinction, they are observed to burn under nearly Zone I conditions, and in this model the additional diffusional resistance associated with ash has little effect.

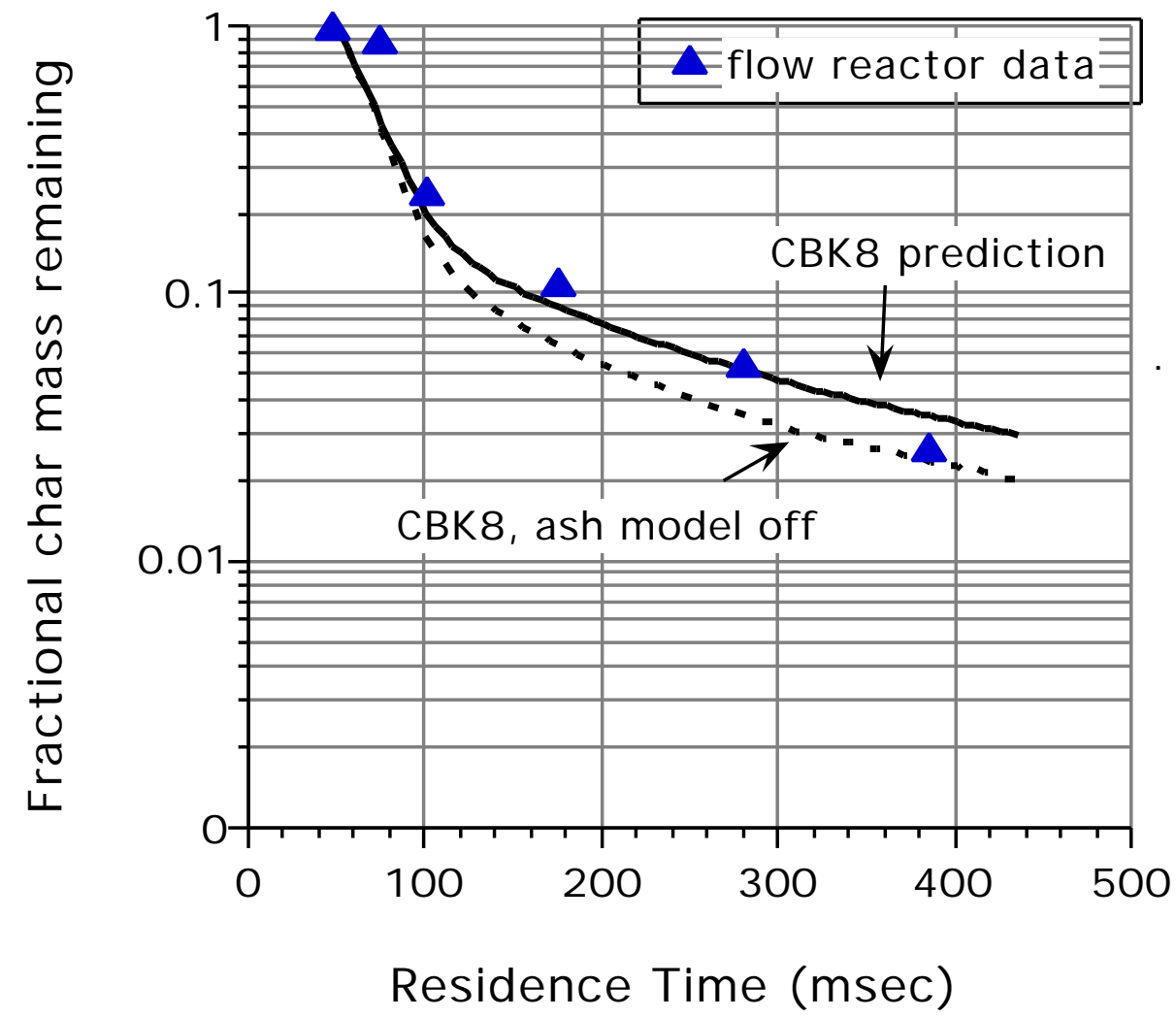

Figure 1. Combustion data for Illinois \#6 coal taken in the hot wall entrained flow reactor at Sandia National Laboratories [Hurt et al., 1998]. 
Figure 2 shows calculations for a lignite under identical conditions. The same model parameter were used in Figs. 1 and 2, the only difference being the initial char reactivity, which of course is significantly higher for the lignite. Here the char reactivity is too high to bring about extinction and thus the break in the mass loss curve by the organic mechanism - the near extinction event is delayed until higher conversions where it is caused by the high concentration of ash. This prediction is in good agreement with the data in Fig. 2.

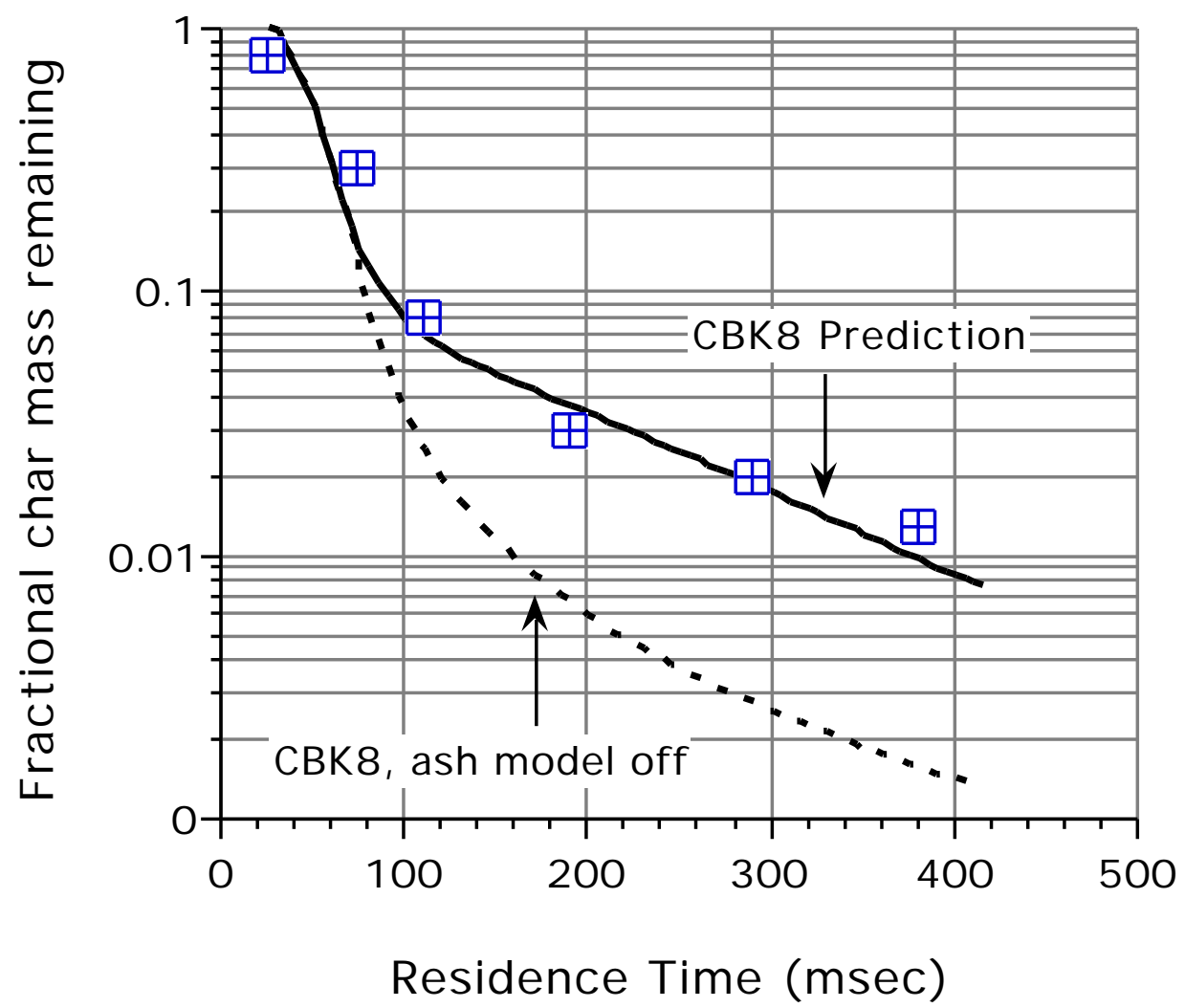

Figure 2. Combustion data for Lower Wilcox lignite taken in the hot wall entrained flow reactor at Sandia National Laboratories [Hurt et al., 1998].

The new model was also applied under conditions typical of the captive particle imaging experiments ( $1250 \mathrm{~K}$ gas temperature) to see if the observed rank trends could be reproduced. At these lower temperatures, most mineral grains do not fuse, and the ash particles are observed to retain a lacy, irregular appearance. Based on this observation, a low packing fraction was used in the ash model under these conditions. In agreement with observations, CBK8 predicts no extinction for the lignites under these conditions, but clear extinction for the bituminous coal chars. This rank-dependent difference is predicted to be a natural consequence of the higher reactivity of the low rank chars - they do not enter Zone I and retain their high Zone II reactivities through the burnout process. The bituminous chars enter Zone I upon decrease in size and reactivity, causing 
an extinction event and a long final burnout tail. No rank-dependent adjustable parameter is required to explain this difference.

In summary, accounting for the Zone II / I transition appears to improve CBK's ability to describe rank-dependent extinction behavior, both at low gas temperatures $(1250 \mathrm{~K})$ and at higher gas temperatures $(1450-1650 \mathrm{~K})$. More work is needed to test and validate CBK8 prior to its release. More work is also needed to incorporate the structural information (porosity and effective diffusivity) into the generalized kinetic framework of CBK. When this work is complete, the full equation set, that data validation, and a more complete study of extinction behavior will be presented in future reports. This work is a clear example of the need for structure based models information on char macrostructural (pore structures and effective diffusion coefficients) is now believed to be required to explain late stage effects for coals of various rank.

\section{References for Section 1}

Field, M. A. Comb and Flame 14:237 (1970).

Hurt, R. H. and R. E. Mitchell 24th International Symposium on Combustion, The Combustion Institute, Pittsburgh, PA, pp. 1243 - 1250 (1992)

Hurt, R.H., Sun, J-K, and Lunden, M., "A Kinetic Model of Carbon Burnout in Pulverized Coal Combustion," Combustion and Flame, 113 181-197 (1998).

Hurt, R.H., Davis, K.D., "Percolative Fragmentation and Spontaneous Agglomeration," Combustion and Flame, in press, 1998.

Mitchell, R.E., Madsen, O.H., Twenty-first Symposium (International) on Combustion, The Combustion Institute, Pittsburgh, 1986, p. 173.

\section{Section 2: Order Length Scales in Carbon Structure Simulations}

Earlier reports described a dynamic model of orientational order / disorder transitions, developed in collaboration with Allan Kerstein, and its application to the formation of char structures. This period we continued our analysis of the simulation results with emphasis on deriving a measure of the length scale of order in the frozen images.

In general, the extent of orientational order in a set of lines whose two ends are indistinguishable is characterized by the nematic order parameter [De Gennes and Prost, 1992], which in two dimensions takes the form:

$$
S=2<\cos ^{2} \theta_{i}>-1
$$

where $\theta_{i}$ is the angle between the vector of preferred orientation (the "director"), and the orientational unit vector of layer $i$, and the angled brackets denote an average over all objects. The 
director itself can be found from the set of unit vectors defining the orientation of the layers by solution of the eigenvalue problem [Hicklas et al., 1994]:

$$
Q \overrightarrow{\mathrm{d}}=\lambda \overrightarrow{\mathrm{d}}
$$

where $d$ is the director and $Q$ is the order tensor:

$$
Q \equiv(1 / N) \sum\left[\begin{array}{cc}
x_{i} x_{i}-1 / 2 & x_{i} y_{i} \\
y_{i} x_{i} & y_{i} y_{i}-1 / 2
\end{array}\right]
$$

where $x_{i}$ and $y_{i}$ are the endpoints of the unit directional vectors for object $i$. For an infinite set of layers, $S$ has a value of zero for random lines (complete disorder) and a value of one for a set of lines all parallel to the director (perfect order). This definition is inadequate for small sample sets, as even sets of randomly chosen lines have mean order parameters systematically greater than zero. In particular, for sets of random line pairs, $(n=2)$, the expected value of the order parameter is not zero but $2 / \pi$ [Shim et al., 1998]. The effect arises when the director is not known apriori, but must be determined from the given set of lines. The choice of the director from the small set of lines biases the result in favor of apparent order, an effect that decreases rapidly as sample size increases. The function that represents the expected value of the order parameter for $n$ random lines, $f_{\text {ran }}(n)$, has been determined numerically and has been used to define a new order parameter, valid for small sample sets [Shim et al., 1998] as:

$$
S(n)=\frac{S-f_{\text {ran }}(n)}{1-f_{\text {ran }}(n)}
$$

This definition is particularly useful when calculating length-dependent order parameters, which for small length scales necessarily involve small sample sizes. The length-dependent order parameter is a useful tool for describing short-range polycrystalline order such as is found in the frozen state in Figure 3.

In previous reports, overall order parameters, $S\left(L_{b o x}\right)$, for the frozen states were plotted as a function of $M^{*}$, showing a clear transition from order to disorder in a critical range of the mobility / growth ratio from $10^{2}$ to $10^{4}$. The evaluation of $S$ at $L_{b o x}$ is, however, an arbitrary choice dependent on the size of the simulation. The same results are presented in Fig. 1 in a more general form as the length scale of ordered structures vs. $M^{*}$. The length scale of order, $L_{o r}$, is derived from plots of length-dependent order parameter, $S(r)$, vs. $r$, the radius of the circular region of interest. $S$ decreases monotonically with $r$ and $L_{o r}$ is defined here as the size of the circular region (2r) at which $S$ has fallen to 0.2. The length scale of order is shown in Fig. 1 to rise rapidly in the $\log M^{*}$ range from 0 to 2 . Strong correlations have been reported between coke reactivity and the size of the anisotropic domains, analogous to the length scale in Fig. 1. Figure 1 is thus a key result from the model, providing a mechanistic basis for estimating the effect of layer mobility on char reactivity. 


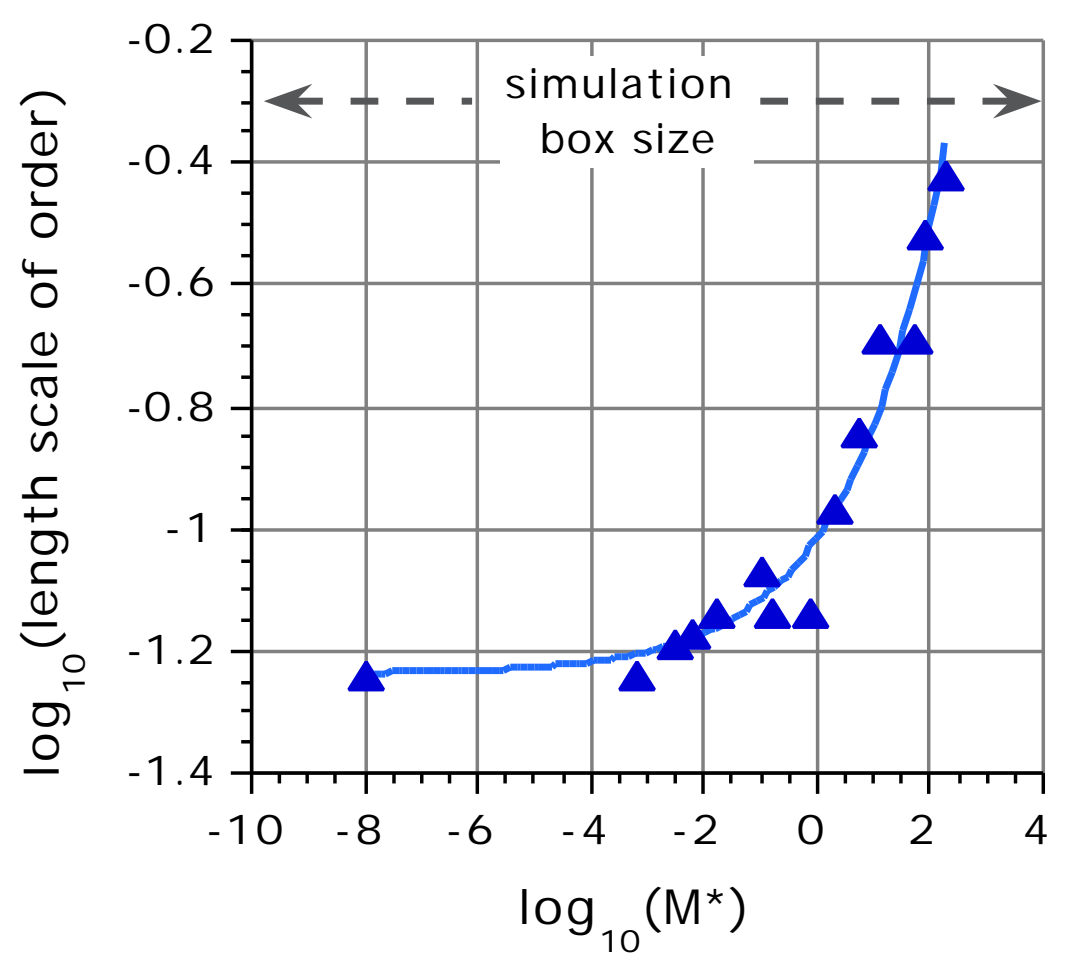

Figure 3. Results from dynamic simulation of orientational order/ disorder transitions. The length scale of orientational order is plotted as a function of dimensionless mobility-to-growth ratio.

\section{References for Section 2}

De Gennes P.G., Prost, J., The Physics of Liquid Crystals, Clarendon Press, Oxford, 1993.

Hicklas, K., Bopp, P., Brickmann, J., J.Chem. Phys., 101 3157-3171 (1994).

Shim, H.S., Hurt, R.H., Yang, N.Y.C. "A Methodology for Analysis of 002 LF Fringe Images and its Application to Combustion-Derived Carbons", submitted to Carbon, 1998. 


\section{Section 3: Computational Chemistry}

Recently, we have focussed our efforts on preparing some papers for submission to journals and one, entitled " $\mathrm{C}-\mathrm{H}$ and N-H Bond Dissociation Energies of Small Aromatic Hydrocarbons" has already been submitted to the Journal of the American Chemical Society. That paper summarizes our efforts to quantify which positions in monocyclic and polycyclic aromatic hydrocarbons (PAHs) will be most susceptible to $\mathrm{H}$ atom loss by some abstracting agent. As presented in previous reports, we have calibrated the efficiency of density functional theoretical methods $[1,2,3,4]$ to calculate the properties and energies of aromatic systems. Other papers are currently in preparation and will be submitted in due course.

In this quarter, we have also spent some effort attempting to rationalize some of the experimental and computational disagreements for the $\mathrm{C}-\mathrm{H}$ bond dissociation energies (BDEs) in pyrimidine. Kiefer and coworkers[5] have reported that the $\mathrm{C}-\mathrm{H}$ bond between both nitrogens should have a lower BDE than the $\mathrm{C}-\mathrm{H}$ bond adjacent to a single nitrogen in pyridine. They rationalize their results as two nitrogens (with their lone pairs) will be able to stabilize an adjacent carbon-centered radical to a greater degree than only one nitrogen. However, all computational methods to date (by us and others[6]) indicate that this experimental report may be in error.

In order to understand this problem, we have embarked on a simple model comparison for pyridine and pyrimidine. One might expect that the $\mathrm{C}-\mathrm{H} \mathrm{BDE}$ in pyrimidine should be lower than that in pyridine if the lone-pair delocalization effect was the only operating factor. In pyridine and pyrimidine, the aromatic ring remains planar in the radicals derived from $\mathrm{H}$-atom abstraction. We

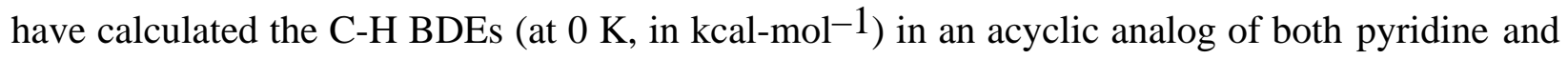
pyrimidine, and they are shown schematically in Figure 1.

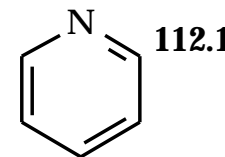

pyridine

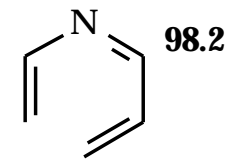

pyridine analog

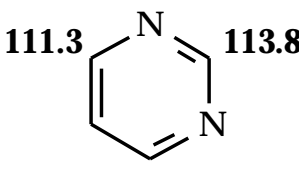

pyrimidine

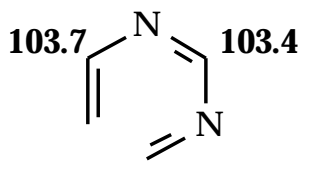

pyrimidine analog

Figure 1. C-H BDEs in cyclic and acyclic systems (at $0 \mathrm{~K}$, in kcal-mol ${ }^{-1}$ ). 
It can be seen that even in the acyclic pyrimidine analog, the $\mathrm{C}-\mathrm{H}$ bond adjacent to both nitrogens is not significantly lower in BDE as compared to the $\mathrm{C}-\mathrm{H}$ bond adjacent to only one nitrogen. The $\mathrm{C}$ $\mathrm{H} \mathrm{BDE}$ is lower in the pyridine analog as compared to the pyrimidine analog.

Furthermore, the carbon-centered radical in the pyridine analog is planar, but the radicals for the pyrimidine analog do not remain planar. Instead the planar structures are transition states, and non-planar structures are preferred. The aromatic systems are "forced" to remain planar, while the acyclic systems can twist from planarity if there is a repulsive effect present. Therefore, while the presence of a nitrogen lone pair is beneficial in order to stabilize the carbon-centered radical, there is also a lone-pair repulsion effect when there are two nitrogens present. This effect was neglected by Kiefer and coworkers,[5] and the repulsive effect seems to be significant.

We have also continued our investigation of cleavage of aromatic ring systems after $\mathrm{H}$ atom addition to the ring. Some aromatic systems seem to oxidize by addition of radicals to the ring as compared to $\mathrm{H}$-atom abstraction. We are examining these preferences at the moment. However, we have not completed this study, and we will present more information in our next quarterly report.

However, we have also attempted to analyze some coal and char samples as generated by our collaborators, Heather Klimesh and Robert Essenhigh. They have been able to provide some representative coal and char samples for us to examine, and we have begun to explore different chemical and spectroscopic analyses for quantitative and qualitative characterization. The char samples have been generated in Essenhigh's high heating rate furnace.

Initially, we have had some initial success with X-ray photoelectron spectroscopy[7] and the results are presented in Figures 2 (coal) and 3 (char). The XPS analysis provides information about the surface characteristics and chemical bonding for both samples. The most interesting feature of the spectra is that the coal and char samples look particularly similar. Both samples have distinct and significant oxygen signatures. The carbon content peak in the char sample is sharper and narrower. Very little nitrogen is present in the coal and even less remains in the char.

The narrow carbon peak indicates that the different kinds of carbon which were present in the coal have been minimized and there are a smaller number of carbons in the char. Presumably this kind of carbon is graphitic and/or aromatic. The relative yield of $\mathrm{C}$ and $\mathrm{O}$ is relatively similar between the coal and char samples with $\mathrm{C}$ being about $85 \%$ and $\mathrm{O}$ being about $13 \%$ in each sample. 
We will continue to examine these coal and char samples with a variety of spectroscopic methods, and these analyses will be presented in due course.

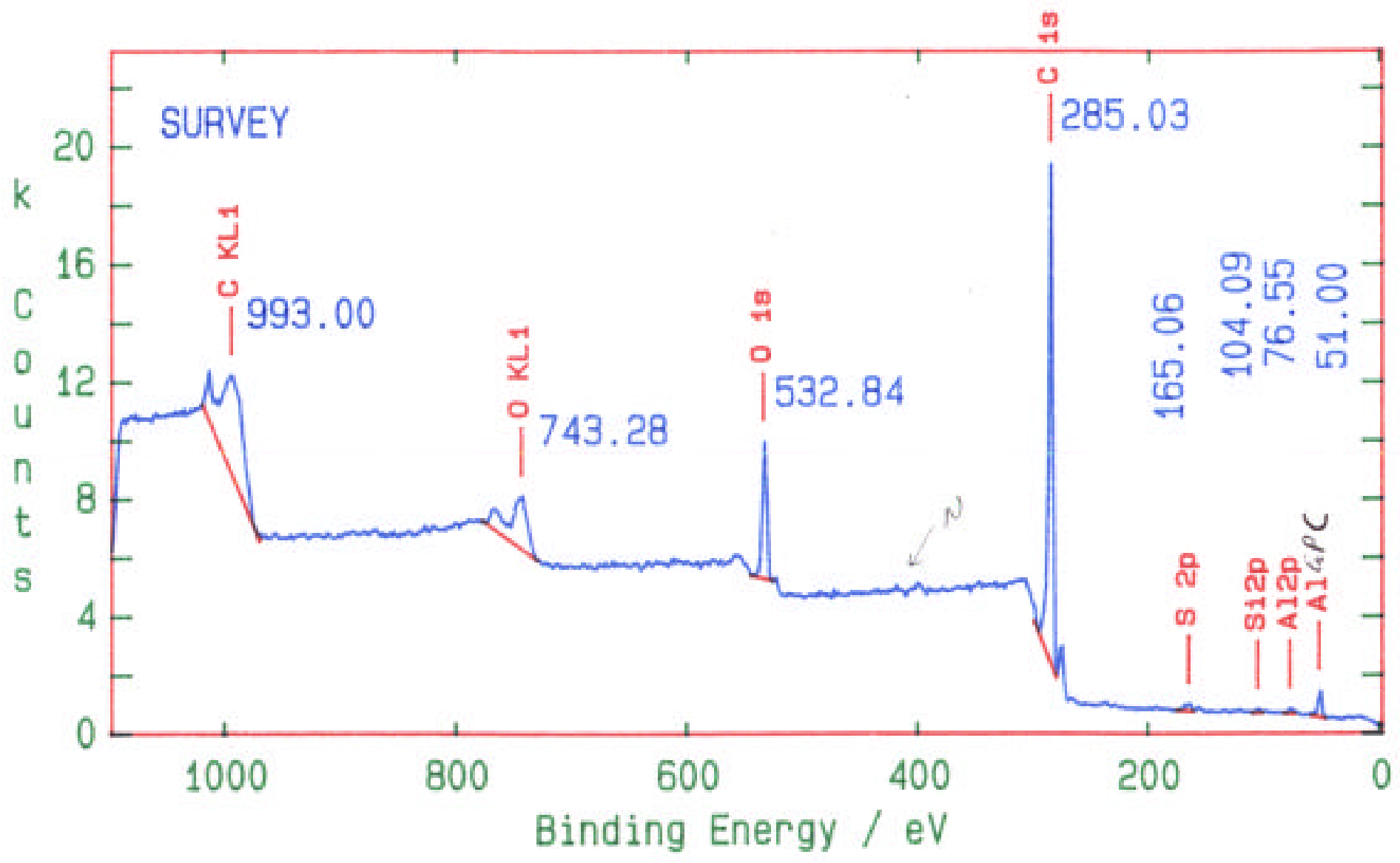

Figure 2. XPS spectrum of a coal sample which was provided by Klimesh and Essenhigh. 


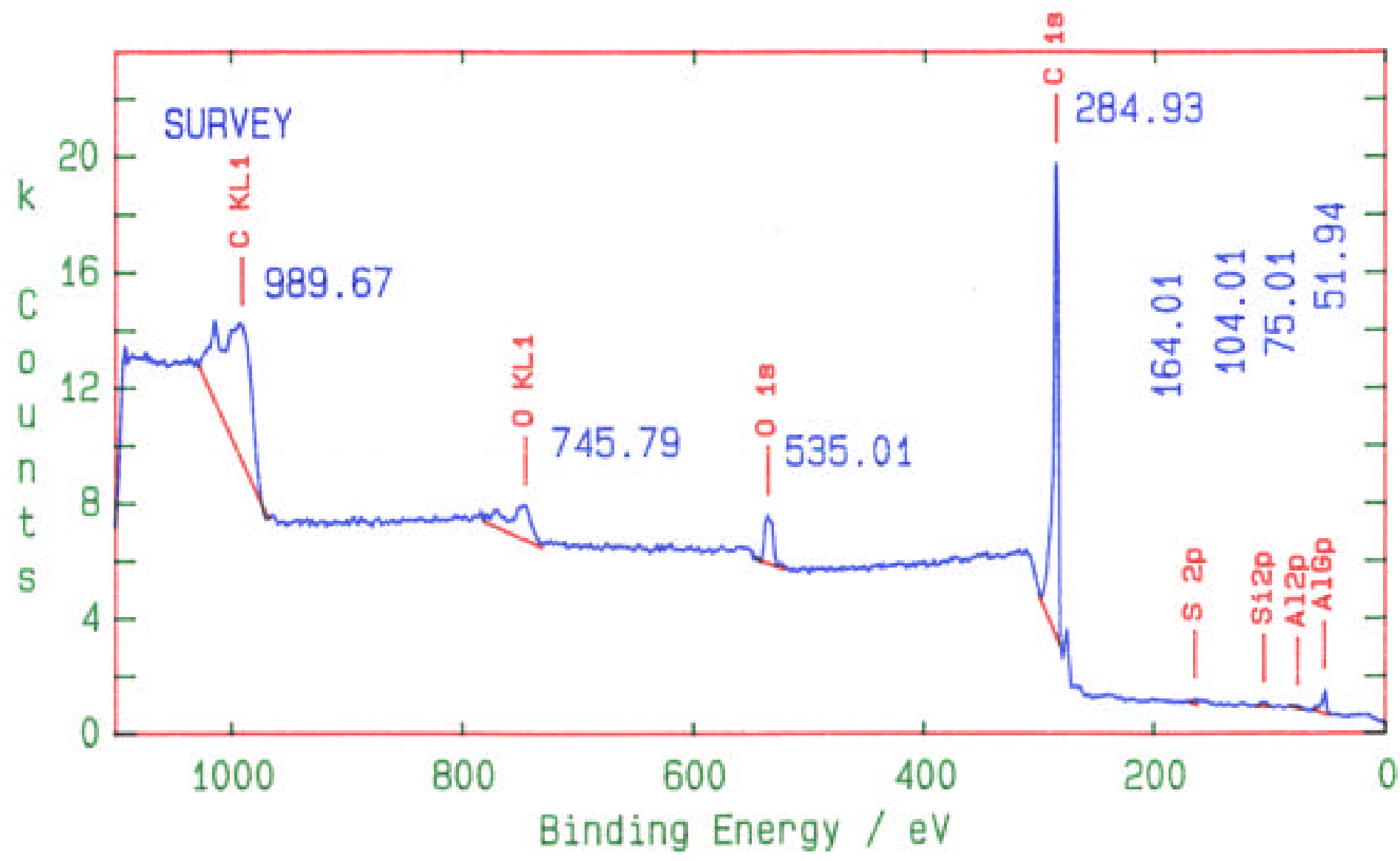

Figure 3. XPS spectrum of a char sample which was provided by Klimesh and Essenhigh.

\section{References for Section 3}

[1] Ziegler, T. Chem. Rev. 1991, 91, 651. Density Functional Methods in Chemistry; Labanowski, J.; Andzelm, J., Eds.; Springer-Verlag: New York, 1991. Parr, R. G.; Yang, W. Density-Functional Theory of Atoms and Molecules; Oxford University Press: New York, 1989.

[2] (a) Becke, A. D. J. Chem. Phys. 1993, 98, 5648 and references therein. (b) Lee, C.; Yang, W.; Parr, R. G. Phys. Rev. B 1988, 37, 785. (c) Stephens, P. J.; Devlin, F. J.; Frisch, M. J. J. Phys. Chem. 1994, 98, 11623. (d) Johnson, B. G.; Gill, P. M. W.; Pople, J. A. J. Chem. Phys. 1993, 98, 5612 5626.

[3] Sulzbach, H. M.; Schleyer, P. v. R.; Jiao, H.; Xie, Y.; Schaefer, H. F. J. Am. Chem. Soc. 1995, 117 , 1369.

[4] Cioslowski, J.; Liu, G.; Martinov, M.; Piskorz, P.; Moncrieff, D. J. Am. Chem. Soc. 1996, 118 , 5261. 
[5] (a) Mackie, J. C.; Colket, M. B, III; Nelson, P. F. J. Phys. Chem. 1990, 94, 4099. (b) Doughty, A.; Mackie, J. C. J. Chem. Soc. Faraday Trans. 1994, 90, 541. (c) Kiefer, J. H.; Zhang, Q.; Kern, R. D.; Yao, J.; Jursic, B. J. Phys. Chem. 1997, 101, 7061.

[6] Jones, J.; Bacskay, G. B.; Mackie, J. C.; Doughty, A. J. Chem. Soc. Faraday Trans. 1995, 91 , 1587.

[7] Klauber, C. Microbeam Anal. 1995, 4, 341.

\section{Section 4: Combustion Experiments in Contrasting Flame Types}

\section{$\underline{\text { Summary }}$}

The High Intensity furnace has been successfully fired. Solid samples have been collected at each of the eleven sampling ports and TGA have been performed on each char using equipment available in the Chemistry Department, as detailed below. The current focus is on overhauling the two-color pyrometer system and the gas analyzers.

\section{Furnaces}

High Intensity (HIT) Tower Furnace

The HIT has been successfully fired; a schematic is attached. Basically, it is a vertical refractory shaft, approximately $2 \mathrm{~m}$ high, with uniform square cross section from top to bottom. The walls are $6.4 \mathrm{~cm}$ thick. It is fired from the top. It is equipped with 11 sampling ports with thermocouples located on the adjacent wall coinciding with the port centers.

\section{Ancillary Equipment}

$\underline{\text { TGA }}$

The TGA in the Analytical Chemistry Department has been used to determine reactivity of char samples obtained form the HIT furnace. Further experiments are needed, as well as corroborating evidence from the co-investigators in the Chemistry department.

\section{Coal Feeder}

The feeder system has been successfully calibrated. During the first firing of the furnace, we estimate that the furnace was burning approximately $20 \mathrm{lb} / \mathrm{hr}$.

\section{Firing Conditions}

The air rate was determined as about $40 \mathrm{scfm}$ resulting in firing at a rich stoichiometry of about 2 (approx. $-50 \%$ excess air). The fuel rich firing condition was used to generate char below the primary combustion zone for study of its thermal annealing behavior, as set out above, 


\section{Temperature Measurement Equipment}

Wall temperatures are obtained with thermocouples; gas temperatures with optical pyrometry. Wall thermocouples have given an accurate temperature profile. The 2color pyrometer is functioning and in the process of calibration.

\section{Gas Analysis}

The $\mathrm{CO}_{2}, \mathrm{O}_{2}$, and $\mathrm{NOx}$ analyzers are on site. We have placed an order for a $\mathrm{CO}$ analyzer. The analyzers are currently being repaired where necessary and calibrated.

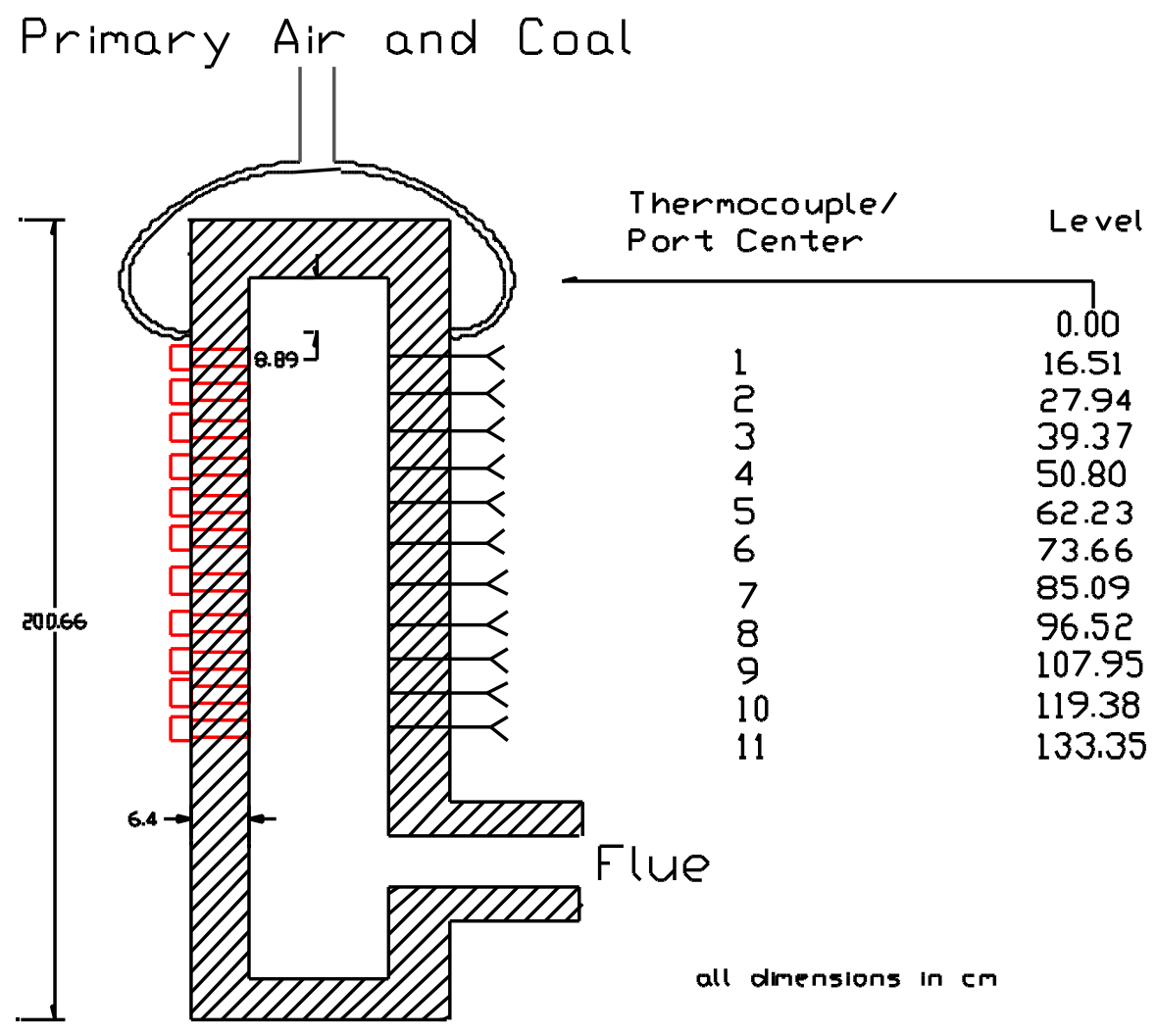

Figure 1. Furnace 